\title{
Fluorescence Spectroscopy Analysis of the Bacteria-Mineral Interface: Adsorption of Lipopolysaccharides to Silica and Alumina
}

\author{
Fateh El-Taboni, Emily Caseley, Maria Katsikogianni, Linda Swanson, Thomas Swift,* \\ and Maria E. Romero-González*
}

Cite This: Langmuir 2020, 36, 1623-1632

Read Online

ABSTRACT: We present here a quantification of the sorption process and molecular conformation involved in the attachment of bacterial cell wall lipopolysaccharides (LPSs), extracted from Escherichia coli, to silica $\left(\mathrm{SiO}_{2}\right)$ and alumina $\left(\mathrm{Al}_{2} \mathrm{O}_{3}\right)$ particles. We propose that interfacial forces govern the physicochemical interactions of the bacterial cell wall with minerals in the natural environment, and the molecular conformation of LPS cell wall components depends on both the local charge at the point of binding and hydrogen bonding potential. This has an effect on bacterial adaptation to the host environment through adhesion, growth, function, and ability to form biofilms. Photophysical techniques were used to investigate adsorption of

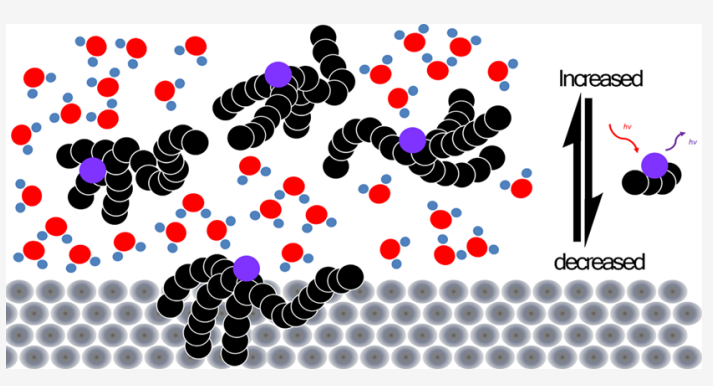
fluorescently labeled LPS onto mineral surfaces as model systems for bacterial attachment. Adsorption of macromolecules in dilute solutions was studied as a function of $\mathrm{pH}$ and ionic strength in the presence of alumina and silica via fluorescence, potentiometric, and mass spectrometry techniques. The effect of silica and alumina particles on bacterial growth as a function of $\mathrm{pH}$ was also investigated using spectrophotometry. The alumina and silica particles were used to mimic active sites on the surface of clay and soil particles, which serve as a point of attachment of bacteria in natural systems. It was found that LPS had a high adsorption affinity for $\mathrm{Al}_{2} \mathrm{O}_{3}$ while adsorbing weakly to $\mathrm{SiO}_{2}$ surfaces. Strong adsorption was observed at low $\mathrm{pH}$ for both minerals and varied with both $\mathrm{pH}$ and mineral concentration, likely in part due to conformational rearrangement of the LPS macromolecules. Bacterial growth was also enhanced in the presence of the particles at low $\mathrm{pH}$ values. This demonstrates that at a molecular level, bacterial cell wall components are able to adapt their conformation, depending on the solution $\mathrm{pH}$, in order to maximize attachment to substrates and guarantee community survival.

\section{INTRODUCTION}

A lipopolysaccharide (LPS) is an amphiphilic macromolecule with a hydrophobic lipid unit embedded in the outer membrane of Gram-negative bacteria. ${ }^{1,2}$ This biologically produced anionic polymer plays an important role in bacterial adhesion, $^{3}$ as it is the major component of the outer membrane of Gram-negative bacteria, ${ }^{4,5}$ the largest group of culturable cells found in aquatic systems. ${ }^{6}$ LPS exhibits a dual role, providing both structural support during adhesion of bacteria to solid surfaces ${ }^{7}$ and acting as a bilayer barrier governing the transport of ions and molecules across the bacteria cell wall. ${ }^{8,9}$ Harnessing the interaction between LPS and metal surfaces has led to recent developments of functional nanomaterials and functional materials designed to target, ${ }^{10}$ sense, ${ }^{11}$ or inhibit ${ }^{12}$ Gram-negative bacteria. It has been reported that LPS plays an important role in the formation of biofilms; ${ }^{13,14}$ a process that is often identified as a key part of bacteria community's survival in soil and aquatic systems, medical devices, and water treatment systems. Bacteria found in a biofilm matrix are less susceptible to drugs than they are in vitro ${ }^{15}$ and this is a known cause of persistence in infections. ${ }^{16}$
LPS coats the outermost layer of many bacteria cell walls and is believed to be a major source of metal binding in Gramnegative bacteria. ${ }^{8,17}$ Bacterial attachment onto surfaces can be affected by many factors including the chemical nature of cell wall components (e.g., LPS, surface proteins, and flagella), surface charge, and $\mathrm{pH} .{ }^{1,18}$ LPS is known to be primarily responsible for bacteria attachment to mineral surfaces. ${ }^{6,19}$ LPS functional groups such as hydroxyl and carboxyl moieties [located on keto-deoxyoctulosonate (KDO) residues in the core oligosaccharide] play a key role in conditioning the LPSsolid interference. ${ }^{1,3,20}$ Phosphoryl groups in this macromolecule, located on the glucosamine lipid, are possibly the most important electrostatic binding sites for metal cations. ${ }^{21}$ Jucker et al. described the hydrogen bonding-driven adsorption of the O-antigen part of LPS chains for titanium dioxide $\left(\mathrm{TiO}_{2}\right)$, aluminum oxide $\left(\mathrm{Al}_{2} \mathrm{O}_{3}\right)$, and silicon dioxide $\left(\mathrm{SiO}_{2}\right)$

Received: July 12, 2019

Revised: November 24, 2019

Published: January 20, 2020 
surfaces and observed greater adhesion for $\mathrm{TiO}_{2}$ and alumina compared to the silica surfaces. ${ }^{22}$

The chances of bacteria attaching to surfaces for the formation of biofilms depend on the success of creating a matrix of suitable composition to match the host environment. This is a dynamic process that, in turn, relies on the availability of nutrients, the secretion of outer cell polymers, shear stress, and social collaboration. Our hypothesis is that at a molecular level, this process also depends on the aqueous $\mathrm{pH}$ and ionic strength because the chemical composition in the solution controls the conformation of cell wall polymeric components and hence sorption to the surface.

With the aim of providing a molecular level understanding of bacterial cell adhesion to mineral surfaces, we examine here the influence of aqueous chemical composition on the molecular conformation of LPS and its sorption to alumina and silica using fluorescence spectroscopy. A novel approach was developed involving the synthesis of fluorescently labeled LPS from Escherichia coli, and the use of fluorescence timeresolved anisotropy measurements (TRAMS) to monitor the conformational behavior of this biopolymer. This was achieved using the fluorescent-labeled 4-amino naphthalene-1-sulfonic acid (AmNS), which was covalently bound to the LPS backbone. AmNS has previously shown to be a reliable reporter of polymer conformation in the solution and has been used to study the adsorption of poly(acrylic acid) onto the surface of calcite. ${ }^{23}$ Adsorption of LPS was studied in dilute ionic solutions as a function of $\mathrm{pH}$ and in the presence of alumina and silica. This approach provides a mechanistic understanding of binding at the interface of the outer cell wall of bacteria and minerals, a process vital to bacterial attachment, growth, and the stability of biofilms.

\section{EXPERIMENTAL DETAILS}

Materials. Deionized double-distilled water (resistivity 18.2 M $\Omega$ $\mathrm{cm})$ was used in all studies. Alumina $\left(\mathrm{Al}_{2} \mathrm{O}_{3}\right)$ was purchased from Sigma-Aldrich with the following characterization parameters: particle diameter: $1363 \pm 73 \mathrm{~nm}$; surface area: $1.11 \mathrm{~m}^{2} / \mathrm{g}$; pH: 8.5 (1 wt \% in water); e.m.f: $-94 \mathrm{mV}$ ( $1 \mathrm{wt} \%$ in water); density: $3.97 \mathrm{~g} / \mathrm{cm}^{3}$. Molecular weight: $101.96 \mathrm{~g} / \mathrm{mol}$. Colloidal silica $\left(\mathrm{SiO}_{2}\right)$ from SigmaAldrich was prepared as a 30 wt \% suspension in water. Characterization parameters were found as follows: particle diameter: $34.7 \pm 1.4 \mathrm{~nm}$; surface area: $225 \mathrm{~m}^{2} / \mathrm{g}$; $\mathrm{pH}$ : 9.2 (1 wt \% in water); e.m.f: $-123 \mathrm{mV}$ ( $1 \mathrm{wt} \%$ in water); density: $1.21 \mathrm{~g} / \mathrm{cm}^{3}$. Molecular weight: $60.08 \mathrm{~g} / \mathrm{mol}$.

Prior to use, AmNS (Aldrich, 97\%) was purified by extraction with warm hexane, the residue was removed and dried under a vacuum over $\mathrm{CaCl}_{2}$. The product (melting point $300-302{ }^{\circ} \mathrm{C}$ ) was stored and refrigerated $\left(5-10{ }^{\circ} \mathrm{C}\right)$ in a dark bottle. The product was isolated with $90 \%$ yield.

LPS from E. coli 0111: B4 (smooth S form, Sigma-Aldrich) was purified by adding an equal volume of chloroform to aqueous solution of LPS, then shaking for $10 \mathrm{~min}$. After that, the aqueous layer was removed, and ethanol was added to precipitate LPS. The LPS was characterized using ${ }^{1} \mathrm{H}$ NMR $\left(400 \mathrm{MHz} \mathrm{D}_{2} \mathrm{O}\right): 4.75,3.8,3.6,3.55$, 2.98, 1.9, 1.1, and $1.0 \mathrm{ppm}$. FTIR spectra (solid): $3330(\mathrm{OH}), 2930$ $(\mathrm{CH}), 1650(\mathrm{CO}), 1085(\mathrm{CN})$, and $1224(\mathrm{CC}) . \mathrm{M}_{\mathrm{N}} 140,900 \mathrm{~g} \mathrm{~mol}^{-1}$, $M_{\mathrm{W}} 287,800 \mathrm{~g} \mathrm{~mol}^{-1}, M_{\mathrm{V}} 258,600 \mathrm{~g} \mathrm{~mol}^{-1}$, and $Ð=2.04 . M_{\mathrm{V}}$ (viscosimetry) $256,800 \mathrm{~g} \mathrm{~mol}^{-1}$. See the Supporting Information for full characterization details.

Polymer Characterization Techniques. ${ }^{1} \mathrm{H}$ NMR analysis was carried out using a Bruker AV-400 instrument at $400 \mathrm{MHz} .{ }^{1} \mathrm{H}$ NMR diffusion studies were recorded on a Bruker AVANCE III $400 \mathrm{MHz}$ nuclear magnetic resonance spectrometer (NMR) equipped with a 5 mm SMART Probe, with diffusion studies with 64 gradient intervals. FTIR analysis was performed using a PerkinElmer Nicolet IS5 FTIR spectrometer. UV analysis was characterized by a Hitachi U-2010 spectrometer, using $1 \mathrm{~cm}$ quartz cuvettes, scanning the range 200$800 \mathrm{~nm}$ with a bandpass of $1 \mathrm{~nm}$. Polymer molecular weight was determined via gel permeation chromatography (GPC) using $2 \times$ DVB-sulfonated JordiGel columns with a refractive index detector (HP 1047A). Samples were injected using a Rheodyne $200 \mu \mathrm{m}$ injection loop at $1 \mathrm{~mL} \mathrm{~min}{ }^{-1}$ in aqueous mobile phase. A Beckman Coulter Optima LE-80K ultracentrifuge set at $5000 \mathrm{rpm}$ was used for centrifugation of solutions. The viscosity average molecular weights were determined by measuring the efflux time of polymer solutions in an Ostwald glass capillary viscometer, thermostated at $30{ }^{\circ} \mathrm{C}$ (all calculations are shown in the Supporting Information).

Synthesis of AmNS-Labeled LPS. LPS was labeled using AmNS by applying a modified procedure first described by Bergbreiter. ${ }^{24}$ LPS $(4.14 \mathrm{~g})$ was dissolved in $80 \mathrm{~mL}$ of deionized water, cooled to $0{ }^{\circ} \mathrm{C}$, and reacted with $18 \mathrm{mg}$ of $\mathrm{N}$-(3-dimethylaminopropyl)- $\mathrm{N}^{\prime}$ ethylcarbodiimide (Sigma-Aldrich) and $11 \mathrm{mg}$ of $\mathrm{N}$-hydroxy succinimide (Sigma-Aldrich) for $30 \mathrm{~min}$. AmNS $(25 \mathrm{mg}$ ) was added and the resulting mixture was stirred overnight. The product was washed with dichloromethane (Sigma-Aldrich), and the aqueous layer evaporated to dryness at a reduced pressure to yield the fluorescently labeled LPS. Samples were ultrafiltrated to remove any small molar mass material through a $10 \mathrm{kDa}$ membrane and lyophilized to give a solid polymer (yield $\sim 90 \%$ ). The obtained molecular weights from GPC were: $M_{\mathrm{N}}$ $132,700 \mathrm{~g} \mathrm{~mol}^{-1}, M_{\mathrm{W}} 305,500 \mathrm{~g} \mathrm{~mol}^{-1}, M_{\mathrm{V}} 270,150 \mathrm{~g} \mathrm{~mol}^{-1}$, and $Ð=$ 2.30. $M_{\mathrm{V}}$ (viscometry) $266,400 \mathrm{~g} \mathrm{~mol}^{-1}$. The ${ }^{1} \mathrm{H}$ NMR and FTIR spectra of AmNS-LPS were identical to the unlabeled LPS because of the low content of fluorophores and high limit of detection of these techniques. Diffusion-ordered spectroscopy ${ }^{1} \mathrm{H}$ NMR studies of the original LPS and AmNS-LPS indicate that the diffusion of the modified polymer did not significantly vary $\left(2 \times 10^{-9} \pm 0.2 \mathrm{~m}^{2} \mathrm{~s}^{-1}, n\right.$ $=6$ ), indicating there was no change to the polymer hydrodynamic radii following the labeling process (Figure S20). ${ }^{3}$ The amount of fluorescent-labeled AmNS ( $\mathrm{mol} \%$ ) was determined from an average of 3 replicate absorbance measurements as $1.55 \mathrm{~mol} \%$ (Std. Dev 0.2 mol \%) (see the Supporting Information).

Adsorption Experiments. Aqueous LPS solutions were prepared at $\mathrm{pH}$ values ranging from 2 to 11 . The solution $\mathrm{pH}$ was adjusted as required using $0.001 \mathrm{M} \mathrm{NaOH}$ or $\mathrm{HCl}$. Alumina powder was added slowly to a stirring solution of LPS $(10 \mathrm{~mL})$ in a $20 \mathrm{~mL}$ centrifuge tube. The suspensions were then stirred or shaken for $18 \mathrm{~h}$. For alumina measurements equilibrated samples were centrifuged at 5000 rpm for $40 \mathrm{~min}$, the supernatant was removed and centrifuged for another $40 \mathrm{~min}$. Aliquots of the supernatant were removed for further analysis. For adsorption measurements on silica, equilibrated solutions were centrifuged for $2 \mathrm{~h}$ to fully sediment the solid phase from the aqueous phase. The supernatant was withdrawn and examined as detailed below.

Fluorescence Analysis. Fluorescence steady-state analysis was carried out using a Horiba Fluoromax-4 spectrophotometer. Sample excitation was performed on fluorescently labeled LPS-mineral samples both before and after separation by centrifugation to determine polymer isolation from the supernatant. The amount of adsorbed LPS was calculated from the difference in the maximum fluorescence intensity of emission in counts per second; all measurements were taken on the same day to ensure an equivalent detector response. Time-correlated single-photon counting fluorescence measurements were carried out on fluorescently labeled LPSmineral samples using an Edinburgh Instruments 199 fluorescence spectrometer. Samples were excited at $370 \mathrm{~nm}$ (using a pulsed HORIBA nanoLED) with the monochromator set to detect fluorescence at $450 \mathrm{~nm}$. A silica prompt (designed to scatter light at the incident wavelength) was run after each sample to consider scattered light from the source during fluorescence analysis and the fluorescence decay reconvoluted to minimize interference in the decay profile. An additional detection channel using dual polarizers was used to record TRAMS of the same samples. The instrumentation and methodology used is the same described in our previous polymeric research. ${ }^{23,25}$ In this instance, the time range of the detector was set to 
Scheme 1. Functionalization of 2-Keto-3-deoxy Octanoic Acid (KDO) Functional Groups on the LPS Backbone Using AmNS

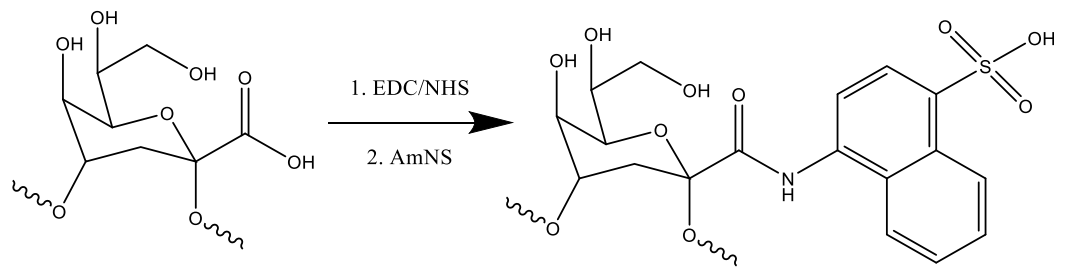

100 ns following excitation, and at peak emission channels, 20,000 counts were obtained for time-resolved measurements.

Potentiometric Titrations. Potentiometric titrations were conducted according to a previously published protocol. ${ }^{26}$ The titrations of LPS samples were carried out at $25^{\circ} \mathrm{C}$ using $0.1 \mathrm{M} \mathrm{NaCl}$ (Sigma-Aldrich) as the background electrolyte. The polymer solution was prepared by dissolving a known amount of the polymer in degassed ultrahigh quality (UHQ) water. Solutions of $0.1 \mathrm{M} \mathrm{NaOH}$ (Sigma-Aldrich) and $0.1 \mathrm{M} \mathrm{HCl}$ (Sigma-Aldrich) were prepared from $\mathrm{NaOH}$ and $\mathrm{HCl}$ using $\mathrm{UHQ}$ water, and the exact concentration determined prior to the titration against $\mathrm{Na}_{2} \mathrm{~B}_{4} \mathrm{O}_{7} \cdot 10 \mathrm{H}_{2} \mathrm{O}$ as a primary standard (Sigma-Aldrich). The samples were dissolved in $25 \mathrm{~mL}$ of the $\mathrm{NaCl}$ electrolyte $(0.1 \mathrm{M})$, and the solution was purged with $\mathrm{N}_{2}$ (>99.99\%) for approximately $1 \mathrm{~h}$ to remove $\mathrm{CO}_{2}$ before initiating titration, yielding a constant $\mathrm{pH}$ value. Following the equilibration procedure, a positive pressure of $\mathrm{N}_{2}$ was maintained by allowing a gentle flow of $\mathrm{N}_{2}$ into the headspace during the titration. The sample solutions were acidified to $\mathrm{pH} \approx 2$ using $0.1 \mathrm{M} \mathrm{HCl}$ and then titrated to $\mathrm{pH} \approx 11$ using $0.1 \mathrm{M} \mathrm{NaOH}$. A control sample without LPS was also titrated. To assess reversibility and protonation behavior, a reverse acidimetric titration was applied following the base titration. Each experiment was carried out in triplicate. All titrations were performed in a glass vessel with the lid as a part of a Metrohm 718 STAT-Titrino instrument at $25{ }^{\circ} \mathrm{C}$. Successive addition of an acid or base was carried out using an auto titrator every $20 \mathrm{~s}$. The electrode was standardized on a proton concentration scale, $\left[\mathrm{H}^{+}\right]$, and the slope deviation from the theoretical Nernst value was always within $1 \%$.

Inductively Coupled Plasma Mass Spectrometry Analysis. For the inductively coupled plasma mass spectrometry analysis (ICPMS), a PerkinElmer ELAN 400 DRC II was used to determine the amount of unreacted minerals according to the following method: the equilibrated mineral LPS solution was transferred into an ultrafiltration cylinder (pore size $1 \mathrm{kDa}$ ), and free mineral passed through a filter and collected in a flask. The eluant was diluted and acidified $\left(1 \% \mathrm{v} / \mathrm{v} \mathrm{HNO}_{3}\right)$, and ICP-MS analysis was carried out. The adsorbed mineral amount was calculated by the difference between the initial concentration and the amount of free mineral in the solution at the end of the experiment.

Bacterial Growth. E. coli (NCCTC 12923) was grown overnight on tryptic soya agar (TSA) and subcultured in the tryptic soya broth. Colony forming units (cfu) $\mathrm{mL}^{-1}$ at a $10^{4}$ concentration were transferred into each 96 well plate and prepared to either 0.2 or $2 \mathrm{wt}$ $\%$ silica/alumina concentrations at varying $\mathrm{pH}(2-10, n=5$ at each $\mathrm{pH}$ value). The absorbance was recorded $24 \mathrm{~h}$ later at $570 \mathrm{~nm}$, using a Thermo Scientific Multiscan FC microplate photometer, and correlated to bacterial growth via a calibration curve. Bacterial suspensions were also plated on TSA toward the production of the calibration curve. Bacterial growth in the presence of silica or alumina particles was also confirmed through growth on TSA. Bacterial growth at $\mathrm{pH} 2$ and $\mathrm{pH} 10$, in the presence or absence of particles, was confirmed through plating on TSA.

\section{RESULTS AND DISCUSSION}

Biologically sourced LPS (S form) was labeled using AmNS via the reaction shown in Scheme 1. The obtained AmNS-LPS exhibited a slightly broader, larger molar mass distribution than the raw LPS polymer because of the addition of AmNS moieties. Functionalization was targeted at $<1 \%$ weight $\%$, to reduce self-quenching and minimize dye interference in polymer properties, but large enough so that after purification (removing residual AmNS groups) the modified polymer exhibited absorbance and luminescence following excitation at $370 \mathrm{~nm}$. The presence of the AmNS label could not be confirmed via ${ }^{1} \mathrm{H}$ NMR or FTIR analysis because of inadequate instrument sensitivity.

The photophysical behavior observed during TRAMS is a result of the mobility of the AmNS label attached to the polymer backbone, rotating with the speed of the macromolecule in solution. When the polymer adopts a coil conformation the rotation of the label is restricted, resulting in longer values of correlation time $\left(\tau_{\mathrm{c}}\right)$. Shorter values of $\tau_{\mathrm{c}}$ are associated with an expanded flexible polymeric chain. Therefore, $\tau_{\mathrm{c}}$ reflects the segmental mobility of the dye on the LPS backbone, and can be interpreted as the ratio and strength of polymer adsorption to surfaces compared to dilute solution diffusion. ${ }^{27}$ The $\tau_{\mathrm{c}}$ vales were determined by applying single exponential fits (eq 1$)$, fixing B $\left(r_{\infty}\right)$ to zero.

$$
r(t)=r_{0} \exp ^{-t / \tau_{c}}
$$

where, $\tau_{\mathrm{c}}$ is the correlation time in nanoseconds, which measures the molecular motion within the fluorophore population, and $r_{0}$ is a constant (the limiting anisotropy of the chromophore in the absence of diffusion). For the samples with a high concentration of silica or alumina (10\% wt), the results would show scattering because of the high concentration of the solids. This causes variation on $r_{0}$ values and Chi square goodness of fit. In this study, $r_{0}$ was limited to a maximum value of 0.2 (Table S2) and the data were fitted to single and dual exponential models. There were no differences between the quality of fit using single or dual exponential equations (Figures S20-S22) even considering the scattering interferences and therefore single exponential fittings are reported here. TRAMS are a powerful tool used to disclose macromolecular conformation, and have previously been used to disclose polymer solution rearrangement ${ }^{25,28}$ and binding. $^{23,29}$

Studies of TRAMS show that the polymer undergoes a conformational change between $\mathrm{pH} 2$ and 6 , as shown in Figure 1 (further details shown in Figures S8-S12).

The longer $\tau_{\mathrm{c}}$ values at $\mathrm{pH} 2-3$ are indicative of a collapsed slow-moving globular structure and the shorter values obtained at a $\mathrm{pH}$ higher than 6 represent the behavior of expanded polymeric chains. Similar behavior has been observed in other $\mathrm{pH}$ responsive polymers, ${ }^{23,30}$ where the adoption of a small globular polymer chain conformation or micelles is preferred over aggregation because of repulsion between polymer chains because of excess protonation. The presence of excess protons in the surface of globes generate a local positive charge that hinders aggregation. ${ }^{30}$

LPS contains phosphate and carboxylate groups within the internal oligosaccharide polymer backbone that are sensitive to 
A)

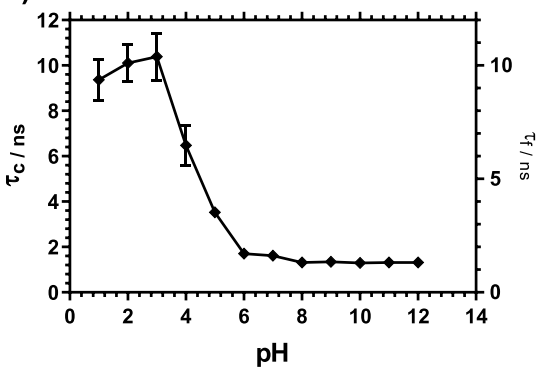

B)

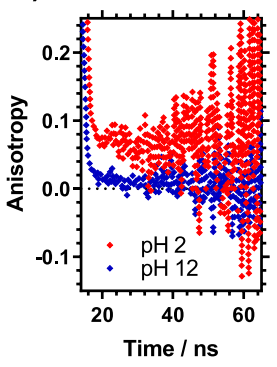

Figure 1. (A) Correlation time $\left(\tau_{\mathrm{c}}\right)$ of AmNS-LPS in aqueous solution plotted between $\mathrm{pH} 1$ and 12. (B) Fluorescence anisotropy decays at $\mathrm{pH} 2$ and 12 , respectively.

changes in the $\mathrm{pH}$ of the solution. ${ }^{31,32}$ As the $\mathrm{pH}$ of the solution changes, the LPS undergoes a conformational rearrangement because of the deprotonation of acid sensitive groups in the LPS. This results in a gradual expansion of the backbone via chain to chain interactions as the $\mathrm{pH}$ approaches neutral values. At $\mathrm{pH}$ values higher than 6 , the correlation time becomes short because of free rotation of the fluorescent label as a result of adoption of a polymer extended conformation. The changes in polymer conformation from globular to partially collapsed and finally extended chain as a function of increasing $\mathrm{pH}$ induce the exposure of otherwise masked functional groups that could influence sorption potential to different chemical moieties at different $\mathrm{pH}$ values. As a result, at low $\mathrm{pH}$, proton or van der Waals forces, including hydrogen bonding, may control the sorption to surfaces, while at high $\mathrm{pH}$ values, attraction or repulsion due to ionic interactions with phosphate or carboxylate groups may be more dominant. Therefore, the polymer conformation depends on the local aqueous $\mathrm{pH}$, indicating a degree of control over the sorption of LPS to surfaces.

Table 1 lists the $\mathrm{p} K_{\mathrm{a}}$ values of nonlabeled and labeled LPS, estimated from the first derivative of the titration curves. The

Table 1. $\mathrm{pK}$ a Constants and pHpzc of Labeled and Unlabeled LPS as Determined by Titration Curves

\begin{tabular}{lcccc}
\multicolumn{1}{c}{ system } & $\mathrm{pK}_{\mathrm{a}\left(\mathrm{H}_{2} \mathrm{PO}_{4}\right)}$ & $\mathrm{p} K_{\mathrm{a}(\mathrm{COOH})}$ & $\mathrm{p} K_{\mathrm{a}\left(\mathrm{C}-\mathrm{NH}_{2}\right) \text { or }\left(\mathrm{H}_{2} \mathrm{PO}_{4}\right)}$ & $\mathrm{pHpzc}$ \\
LPS & 2.50 & 4.96 & 9.50 & 2.39 \\
AmNS-LPS & 2.78 & 5.02 & 9.50 & 2.40
\end{tabular}

results obtained for the LPS samples correspond well with previous values reported for functional groups in bacteria: ${ }^{26}$ phosphate (2.50), hydroxyl and/or amine groups (9.50), and carboxyl groups (4.96). The $\mathrm{p} K_{\mathrm{a}}$ values of labeled and unlabeled LPS are comparable, indicating that fluorescently labeled LPS behaves like nonlabeled LPS when external stimuli such as $\mathrm{pH}$ changes. The results also demonstrate that the AmNS label has no effect on the physical and chemical behavior of the macromolecule. The functionalization of LPS with AmNS is then ideal; the label can be used to track the motion of the LPS molecule without altering the behavior of the macromolecule. The presence of the different acid-base reactive functional groups confirms the amphoteric character of LPS. At low $\mathrm{pH}$, phosphate groups may control the sorption behavior of the molecule. At the most common environmental $\mathrm{pH}$ values between 4.5 and 6.5, carboxyl or carboxylate groups will be predominantly reactive, and at higher $\mathrm{pH}$ values, nitrogen-containing groups may be the major contributors to

the sorption process. The environmental $\mathrm{pH}$ is, therefore, critical to the sorption properties of LPS and may be a key control of the mechanism of adhesion of bacterial cell wall components.

Table 1 also shows the point of zero charges (pHpzc) for LPS and AmNS-LPS as estimated from the titration. The point of zero charge is known as the $\mathrm{pH}$ value at which the molecule surface charge is equal to zero. ${ }^{33}$ Therefore, when the $\mathrm{pH}$ value is lower than the value of $\mathrm{pHpzc}$, the surface of the macromolecule exhibits an overall positive charge because of the protonation of functional groups. In contrast, when the $\mathrm{pH}$ value is higher than the pHpzc value, the polymer backbone acquires a negative charge because of the deprotonating of chemical moieties. For example, the protonation-deprotonation behavior of phosphate is proposed to occur as represented in eq 2.

$$
\begin{aligned}
& \mathrm{pH}<\mathrm{pHpzc} \quad \mathrm{pH}=\mathrm{pHpzc} \quad \mathrm{pH}>\mathrm{pHpzc} \\
& \text { LPS }-\mathrm{H}_{3} \mathrm{PO}_{4}^{+} \rightleftharpoons \text { LPS }-\mathrm{H}_{2} \mathrm{PO}_{4} \rightleftharpoons \text { LPS }-\mathrm{HPO}_{4}^{-}
\end{aligned}
$$

The value of pHpzc of labeled and nonlabeled LPS is comparable, indicating that changes in the LPS chain are because of changes in solution $\mathrm{pH}$ and not because of the introduction of AmNS as a label. The surface charge of silica and alumina was also quantified over a range of $\mathrm{pH}$ values using potentiometric titrations. The variation in relative charge density of silica and alumina solutions in the absence and presence of adsorbed LPS is shown in Figure 2. The data

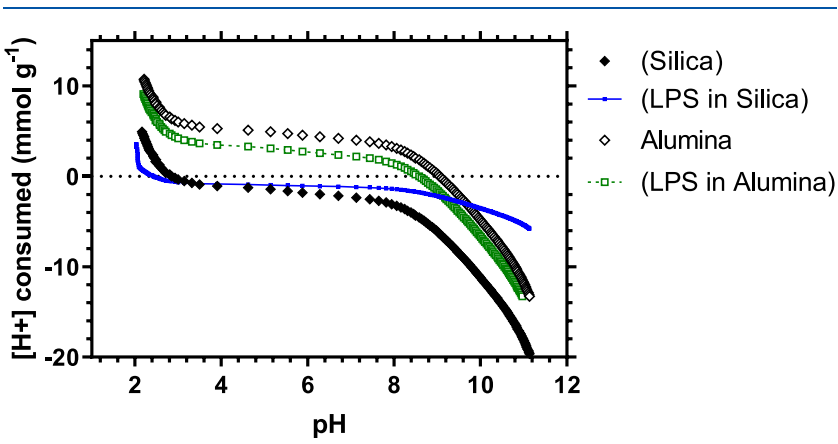

Figure 2. Relative surface charge vs $\mathrm{pH}$ for silica ( $)$, LPS in silica (blue $\bullet$ ), alumina $(\diamond)$, and LPS in alumina (green $\square$ ).

indicate that the adsorption of the multi-ionizable LPS chain decreases the alumina positive charge considerably and lowers the $\mathrm{pHpzc}$ of the alumina from $\sim 9$ to $\sim 8.5$. No considerable effect on the relative charge behavior of silica suspension is noted because the $\mathrm{pHpzc}$ of the silica remains unchanged at approximately 3 after the addition of LPS. These results suggest that electrostatic interactions are mainly responsible for the adsorption of LPS on $\mathrm{Al}_{2} \mathrm{O}_{3}$ particles. The adsorption of LPS on the silica suspension could be attributed to the nonelectrostatic forces which occur between LPS and the silica surface or van der Waals forces including hydrogen bonding interactions.

Figure $3 \mathrm{~A}, \mathrm{~B}$ shows the fluorescence steady-state spectra of control samples of $10^{-5} \mathrm{M}$ AmNS in $1 \mathrm{wt} \%$ silica or $1 \mathrm{wt} \%$ alumina before and after the separation of the solid components by centrifugation at $\mathrm{pH} 2$. In both cases, it was found that the fluorescence intensity values before and after separation were indistinguishable indicating that the free AmNS remains dispersed in the bulk solution and does not 
$1 \mathrm{wt} \%$ Silica
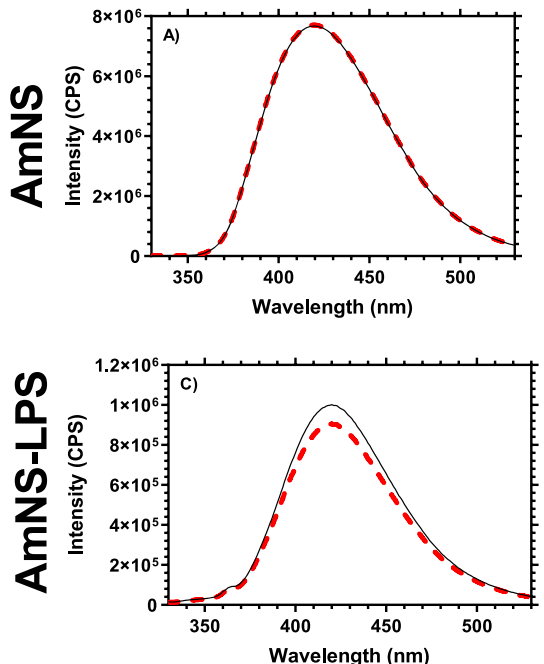

$1 \mathrm{wt} \%$ Alumina
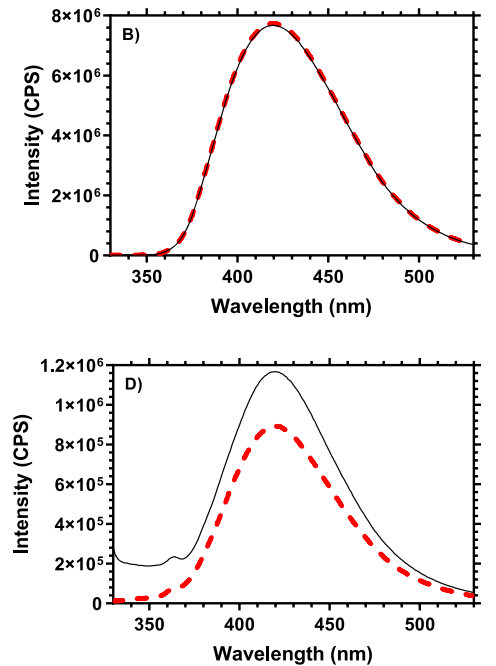

Figure 3. Fluorescence emission scan following fixed excitation $\left(\lambda_{\mathrm{ex}}=320 \mathrm{~nm}\right)$ for AmNS $\left(10^{-5} \mathrm{M}\right)(\mathrm{A}, \mathrm{B})$ and AmNS-LPS $\left(10^{-2}\right.$ wt $\left.\%\right)(\mathrm{C}, \mathrm{D})$ in 1 wt \% silica $(\mathrm{A}, \mathrm{C}) /$ alumina $(\mathrm{B}, \mathrm{D})$, both before (solid black line) and after separation (red dotted line).

interact with the silica and alumina particles. Figure $3 \mathrm{C}$ shows the fluorescence emission spectra for samples of $10^{-2}$ wt \% AmNS-LPS at pH 2 in 1 wt \% silica and Figure 3D shows the results for $1 \mathrm{wt} \%$ alumina. The spectra were recorded before and after centrifuging, as described in the adsorption experiment. In the presence of silica, the supernatant shows a $10 \%$ reduction in fluorescence intensity after centrifugation, and approximately $25 \%$ reduction for the alumina experiment due to sorption of LPS to particulates of either silica or alumina. The difference in fluorescence reduction between silica and alumina indicates that more LPS is sorbed to alumina than silica (however a limiting factor of this technique is the light scattering evident in Figure 3D). From these results, it is evident that the vast majority of the macromolecule remains in the bulk solution and does not adsorb to the particle's surface.

Figure 4 shows the percentage of adsorbed LPS on silica (a) and alumina (b) as a function of $\mathrm{pH}$ at increasing mineral concentration. The amount of AmNS-LPS adsorbed on the solid surfaces was quantified by the peak fluorescence intensity values at $425 \mathrm{~nm}$. The percentage value (\% Ads) was calculated from the fluorescence intensity of the supernatant solution $\left(I_{\text {sup }}\right)$, separated by centrifugation, and the fluorescence intensity of the equilibrated AmNS-LPS/solid $\left(I_{\text {eq }}\right)$. It was assumed that any AmNS-LPS remaining in the supernatant solution was representative of the LPS not adsorbed to the solid surfaces. By mass balance, the sorbed AmNS-LPS was calculated as the difference between free AmNS-LPS in the supernatant solution compared to the total initial concentration of AmNS-LPS in solution as shown in eq 3.

$$
\% \text { Ads }=\frac{I_{\text {sup }}-I_{\text {eq }}}{I_{\text {eq }}} \times 100
$$

The amount of adsorbed AmNS-LPS decreases when the $\mathrm{pH}$ was increased from 2 to 11 . This $\mathrm{pH}$ dependence can be explained in terms of the value of $\mathrm{pHpzc}$ for AmNS-LPS and silica. The pHpzc of AmNS-LPS is 2.4, whereas it is approximately 3 for silica, indicating that the relative charges of $\mathrm{SiO}_{2}$ and AmNS-LPS are both negative from $\mathrm{pH}$ 3-11, causing electrostatic repulsion between LPS chains and the mineral particle. Increasing the $\mathrm{pH}$ values gives rise to the a)
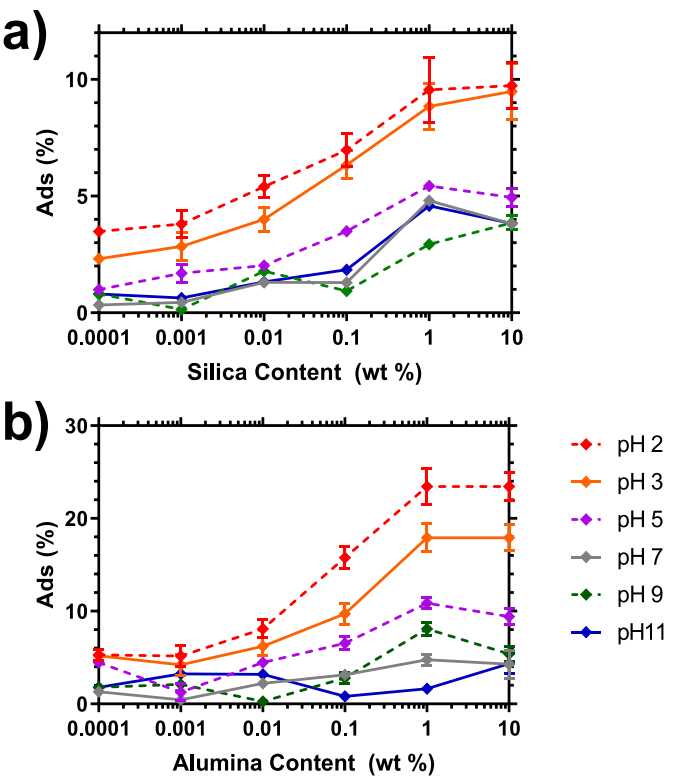

Figure 4. Percentage of adsorbed $10^{-2}$ wt $\%$ AmNS-labeled LPS on silica (a) and alumina (b) at various $\mathrm{pH}$.

overall negative charge of the molecule and the mineral surface, making sorption less favorable. ${ }^{34}$ Similar results have previously been observed for the adsorption of $E$. coli on zeolites containing $\mathrm{SiO}_{2}$ and $\mathrm{Al}_{2} \mathrm{O}_{3}$ particles, ${ }^{35}$ where higher adsorption was observed at acidic conditions favoring electrostatic attraction and adsorption was reduced at basic conditions with increased electrostatic repulsion.

Increasing the amount of silica led to greater amounts of LPS adsorption. There is more LPS sorbed at $\mathrm{pH} 2$ and 3 in solutions containing $10^{-4}$ to $10^{-2}$ wt $\% \mathrm{SiO}_{2}$, while little adsorption was recorded at $\mathrm{pH}$ levels 5, 7, 9, and 11 (Figure 4). When the concentration of the added $\mathrm{SiO}_{2}$ was increased to 1 and $10 \mathrm{wt} \%$, the adsorbed amount reached its maximum (approximately $10 \%$ of LPS adsorption), indicating that the sorption process is also limited by the amount of the mineral surface available. The reduction of LPS adsorbed by $\mathrm{SiO}_{2}$ (despite its significantly increased surface area) could be 
because of repulsion forces at $\mathrm{pH}$ values higher than the pHpzc, and the amount of chemical moieties available to take part in the sorption process and steric effect of O-antigen chains. ${ }^{36}$ Compared to small organic acid chains, ${ }^{23}$ for example, LPS showed low adsorption on silica under similar environmental conditions. This is because of the size and conformation of the LPS macromolecule which may block surface sites preventing sorption on the surface of the mineral particle. This finding highlights the importance of understanding molecular conformation in solution to explain adsorption.

Similarly, the amount of the adsorbed biopolymer on alumina decreased when the $\mathrm{pH}$ value increased from 2 to 11 . The $\mathrm{pH}$ dependence of the adsorption is attributed to both the polymer- and mineral proton-sensitive sites. The $\mathrm{Al}_{2} \mathrm{O}_{3} \mathrm{pHpzc}$ value was 9 , resulting in a net positive charge for the surface of alumina up to $\mathrm{pH} 9$, while the LPS is negatively charged in the $\mathrm{pH}$ range from 3 to 11 . The adsorption of LPS also increased as a function of alumina concentration, from $10^{-4}$ to $10 \mathrm{wt} \%$. A further rise was observed at $\mathrm{pH} 2$ and 3 , as the percentage of adsorbed LPS reaches the maximum value ( $24 \%)$ compared to the small increase in the adsorbed LPS at $\mathrm{pH}$ values of 511. As a result, the electrostatic attraction between LPS and alumina particles are favored between $\mathrm{pH} 3-9$, and an increase in polymer adsorption is due to strong electrostatic attraction of the $\mathrm{COO}^{-}$and/or $\mathrm{PO}_{4}^{-}$groups in LPS with the positively charged alumina group. This adsorption is still weaker than an equivalent smaller polymer molecule [i.e., poly(acrylic acid)], which can be nearly entirely removed from the solution under equivalent conditions. ${ }^{23}$

Comparison of the fluorescence anisotropy decays of AmNS-LPS in water (both in the absence and presence of minerals) and shows that the anisotropy decays rapidly to zero in the absence of mineral particles (Figure 5). In the presence of minerals, the anisotropy does not decay to zero and an anisotropic component that outlasted the lifetime of the excited state measurement was observed.

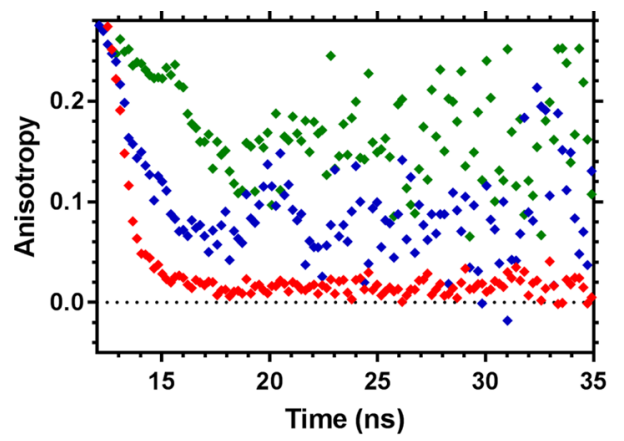

- LPS in water • LPS on silica - LPS on alumina

Figure 5. Fluorescence time-resolved anisotropy data of AmNSlabeled LPS solution $\left(10^{-2} \mathrm{wt} \%\right)$ in the absence of the mineral, at a silica concentration of $10 \mathrm{wt} \%$ and at an alumina concentration of 10 wt $\%$. All samples recorded at $\mathrm{pH} 9, \lambda_{\mathrm{ex}}=370 \mathrm{~nm}$ and $\lambda_{\mathrm{em}}=450 \mathrm{~nm}$.

The effect of the solution composition on the dynamic motion of fluorescently labeled LPS samples on silica and alumina, respectively, was also investigated (Figures S16-S18). The $\tau_{\mathcal{c}}$, values, derived from the anisotropy decays of AmNSLPS $\left(10^{-2}\right.$ wt \%) measured over a wide range of $\mathrm{pH}$ conditions and varying concentration of mineral, are shown in Figure 6. At low concentrations of mineral (i.e., $10^{-4}$ wt \%), LPS-AmNS
A)

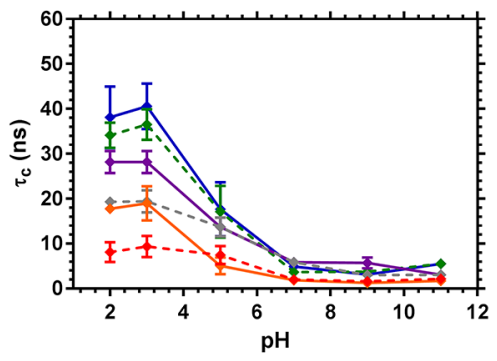

Mineral Content (wto)
$-\$ 0.0001$

$\rightarrow 0.001$

B)

$\rightarrow 0.01$

B)

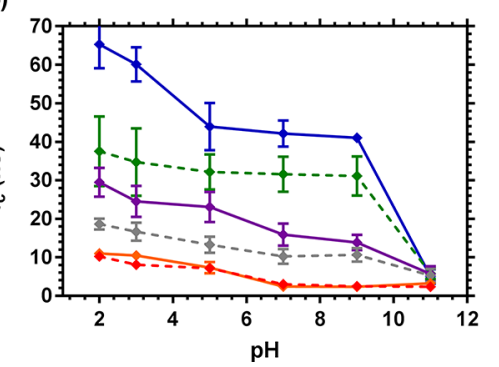

$\rightarrow 0.1$

-.. 1

$\rightarrow 10$

Figure 6. Correlation times for AmNS-LPS (10 $10^{-2}$ wt \%) as a function of the concentration of silica (A) and alumina (B) as a function of $\mathrm{pH}$.

exists in a solvated homogenous environment, with $\tau_{\mathrm{c}}$ values indicative of solvated, isolated single LPS chains in a dilute solution undergoing independent macromolecular motion. ${ }^{37}$ As the concentration of the mineral is increased up to $10 \mathrm{wt} \%$, LPS-AmNS attaches itself to the mineral surface, moving from the bulk solution onto the solid surface resulting in a general increase in the value of $\tau_{\mathrm{c}}$. As the labeled macromolecule adsorbs to the suspended, solid particles, the motion of LPSAmNS is restricted resulting in increased $\tau_{\mathrm{c}}$ values. ${ }^{38}$

The data in Figure 6 corroborate the experiments summarized in Figure 4, where the sorption of LPS-AmNS to silica and alumina was studied by the separation of the solid and liquid phases by centrifugation. The amount in percentage of adsorbed LPS-AmNS, as shown in Figure 4, reveals that the fluorescently labeled LPS adsorbs onto the mineral surface, and a reduced amount of fluorescent materials is left in the supernatant following centrifugation. These experiments reveal (by analyses of the supernatant) that aggregation of the LPSAmNS chains in the aqueous phase cannot occur because there is a general decrease in fluorescence intensity values (which reflects a decrease in labeled LPS concentration) with an increase in the amount of colloidal particles. The increase in $\tau_{c}$ can, therefore, only reflect the adsorption of LPS-AmNS onto the colloidal surface.

The model that we propose, based on the $\tau_{\mathrm{c}}$ data (in Figure 6) in conjunction with the sorption study data (Figure 4), is one in which by increasing the mineral concentration a general increase in $\tau_{\mathrm{c}}$ occurs because of the attachment of LPS-AmNS on the surface.

The results for both silica and alumina (Figure 6A,B) show that at low $\mathrm{pH}(\mathrm{pH} 2-5)$, the value of $\tau_{\mathrm{c}}$ increases with the concentration of minerals in solution (Figure 6), where a higher increase of $\tau_{c}$ values can be observed for the alumina results. At $\mathrm{pH}$ values higher than 7 , no significant changes of $\tau_{\mathrm{c}}$ values were observed with changes in $\mathrm{pH}$ when in the presence of silica. The response indicates adsorption between LPS polymer chains and alumina particles restricting the motion of the molecule and hence increasing the value of $\tau_{c}$. In the case 
of alumina, a dependency of $\tau_{\mathrm{c}}$ values on $\mathrm{pH}$ is evident up to $\mathrm{pH}$ 9. The influence of $\mathrm{pH}$ and mineral concentration on $\tau_{\mathrm{c}}$ demonstrates that there is a stronger sorption process occurring between LPS and alumina compared to silica. The sorption process in the presence of alumina is favorably at a wider range of $\mathrm{pH}$, where attraction forces increase because of opposite surface charge. The availability of surface-sensitive groups also controls the adsorption, and higher adsorption was observed with increasing concentration of mineral, especially in the case of alumina.

Evidence of LPS absorption was further obtained by quantifying the amount of minerals attached to LPS by ICP-MS (Figure S1). The amount of alumina adsorbed to LPS was higher at $\mathrm{pH} 2-9$, indicating favorable adsorption over a wide range of $\mathrm{pH}$ values. The pattern is similar to that obtained for the quantification of LPS using fluorescence (Figure 6) confirming that the sorption process occurs and is controlled by attraction forces at the surface. It is interesting to note that there is little difference between the values of alumina adsorbed at different $\mathrm{pH}$ (Supporting Information 1) compared to the trend and variation on the amount of LPS adsorbed (Figure 4B), indicating changes in the stoichiometry of the reaction as a function of $\mathrm{pH}$. The motion of the biopolymer chain is restricted as a function of the amount of the mineral present. There are similarities in the pattern of variation of $\tau_{\mathrm{c}}$ values for alumina and silica (Figure 6) compared to the amount of mineral adsorbed (Figure S1). This is evidence of the interactions taking place between LPS and mineral particles and the influence of solution $\mathrm{pH}$ on the adsorption process.

Interestingly, the LPS chain can adsorb on alumina, as well as the silica surfaces over the entire studied $\mathrm{pH}$ range, even at $\mathrm{pH}$, where both LPS and solids have repulsive charges. This could be attributed to the fact that nonelectrostatic forces, such as van der Waals attraction dominates over the electrostatic repulsion between adsorbed polyelectrolyte coils and similarly charged surfaces. ${ }^{39}$ Otherwise, the adsorption of an ionizable LPS chain on the negatively charged mineral surface would not be favorable.

Adsorption isotherms were constructed for silica and alumina at $\mathrm{pH} 2-11$ at $10^{-2}$ wt \% LPS solutions, as shown in Figure S2. The Supporting Information shows an example of the isotherm studies at $\mathrm{pH} \mathrm{7,} \mathrm{where} \mathrm{it} \mathrm{can} \mathrm{be} \mathrm{observed} \mathrm{that} \mathrm{the}$ amount of alumina adsorbed on LPS increased with higher concentrations of alumina.

The isotherms showed a similar trend to previous results, where there is a low amount of LPS sorbed to silica compared to alumina. The obtained isotherms were fitted to a linear adsorption model according to eq 4. These linear dependencies enabled the calculation of the distribution constant ( $K_{\mathrm{D}}$ - see Supporting Information) of minerals adsorption from the slope of the Henry's equation $\left(K_{\mathrm{h}}\right)$.

$$
[\text { Solid }]_{\text {adsorbed }}=K_{\mathrm{h}}[\text { Solid }]_{\mathrm{added}}
$$

where, [Solid] adsorbed is the concentration of the adsorbed mineral in $\mathrm{mol} / \mathrm{kg}$, [Solid] added is the concentration of added mineral in $\mathrm{M}$, and $K_{\mathrm{h}}$ is the Henry or affinity constant because a large $K_{\mathrm{h}}$ means that the mineral is strongly adsorbed on the polymer, and vice versa.

The obtained $K_{\mathrm{h}}$ and goodness of fit $\left(R^{2}\right)$ values are given in Table 2. Considering the values of $R^{2}$ the Henry model is suitable for describing these isotherms. The $K_{\mathrm{h}}$ of the Henry
Table 2. Henry (Affinity) Constants $\left(K_{h}\right)$ of Alumina and Silica Adsorbed on LPS and the Goodness of Fit Values $\left(R^{2}\right)$ at Different $\mathrm{pH}$ Values

$\begin{array}{lcccc}\mathrm{pH} & \underline{K}_{\mathrm{h}}(\mathrm{L} / \mathrm{kg})(\text { alumina }) & R^{2} \text { (alumina) } & K_{\mathrm{h}}(\mathrm{L} / \mathrm{kg})(\text { silica }) & R^{2}(\text { silica }) \\ 2 & 0.57 & 0.9999 & 0.09 & 0.9571 \\ 3 & 0.59 & 0.9998 & 0.09 & 0.9613 \\ 5 & 0.29 & 0.9977 & 0.06 & 0.9601 \\ 7 & 0.29 & 0.9977 & 9 \times 10^{-4} & 0.9967 \\ 9 & 2.7 \times 10^{-3} & 0.9999 & 1 \times 10^{-3} & 0.9969 \\ 11 & 4.1 \times 10^{-3} & 0.9993 & 1.1 \times 10^{-3} & 0.9968\end{array}$

model represents a measure of adsorption affinity, where a large $K_{\mathrm{h}}$ reflects stronger adsorption.

Higher values of $K_{\mathrm{h}}$ were obtained for the isotherms at $\mathrm{pH} 2$ and 3 for both silica and alumina, and the values for alumina are significantly higher in the $\mathrm{pH}$ range $2-7$. Overall, the sorption between LPS and silica was shown to be weak and likely a result of van der Waals attractions, as well as hydrogen bonding. Strong adsorption was observed between LPS and alumina most likely due to electrostatic attractions.

This adsorption behavior is similar to that seen in previous studies into polyelectrolyte adsorption, ${ }^{40}$ indicating that electrostatic forces play a large role on mineral surface binding. The formation of ion pairs explains the binding of positively charged molecules to negatively charged surfaces. Near or below the pHpzc, polymeric molecules are bound to surfaces through hydrogen interactions and van der Waals forces. ${ }^{41}$ Scheme 2 shows the possible mechanisms of sorption between the sugar moieties on the LPS and minerals, both above and below the mineral pHpzc. From these results, a general model for sorption of LPS from extra-polymeric substances (EPSs) exudated by bacteria during biofilm formation can be drawn. At low $\mathrm{pH}$, attraction between LPS and alumina surfaces will occur because of electrostatic interactions. The sorption process is particularly favorable at acidic $\mathrm{pH}$, where LPS exhibits an open-chain conformation that induces binding via carboxylate or phosphate groups. High $\mathrm{pH}$ values $(>9)$ impede attraction because of repulsive forces and hence reduce the possibility of a sorption process occurring. In the case of silica, sorption is reduced at most $\mathrm{pH}$ values, expect for the limited range between $\mathrm{pH} 2$ and 4.6 where carboxylate groups are protonated, enabling sorption due to proton interactions and van der Waals forces, particularly at $\mathrm{pH} 2 .{ }^{42}$ In the case of silica, binding occurs via hydrogen interactions at low $\mathrm{pH}$ but requires significantly high concentration of LPS. The sorption process is favored over a wide range of $\mathrm{pH}$ for both silica and alumina; however, over most environmental near-to-neutral $\mathrm{pH}$ values, repulsion occurs, limiting the possibilities of sorption.

The findings from this study indicate that bacteria may need to regulate the composition of LPS as a response to its surroundings to increase the chances of adhesion to mineral surfaces prior to biofilm formation. The results give us an insight into the mechanism of bacteria adaptation to their external environment because the behavior of LPS in solution can be compared to that of the bacteria biofilm. ${ }^{35,43}$ The composition of EPS may then be a response to the mineral surface and $\mathrm{pH}$ of the aqueous environment and therefore producing EPS with the appropriate chemical characteristics maximizes adsorption and guarantee biofilm formation.

To demonstrate the biological relevance and implications of this work, an investigatory study was carried out on E. coli 
Scheme 2. Schematic Representation of the LPS-Alumina/Silica Sorption Mechanism Around pHpzc Transitions

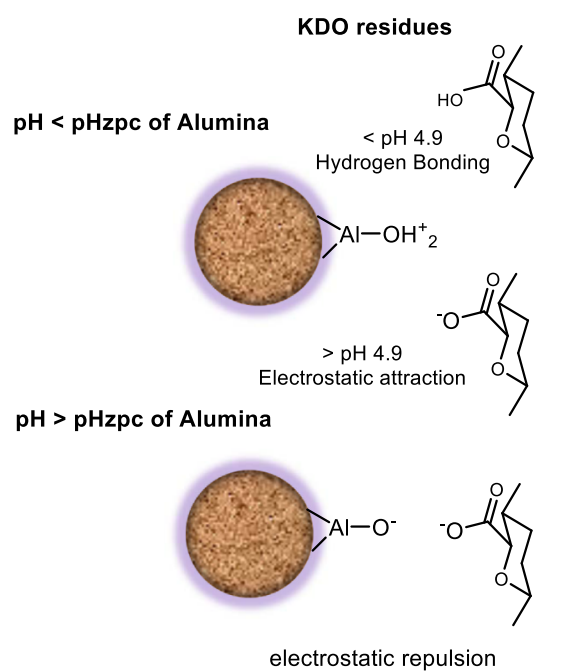

Glucosamine Phosphate Groups

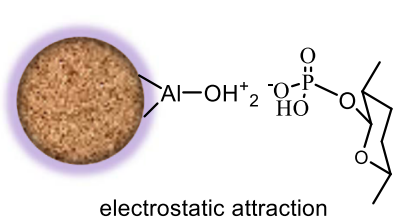

$\mathrm{pH}<\mathrm{pHzpc}$ of Silica

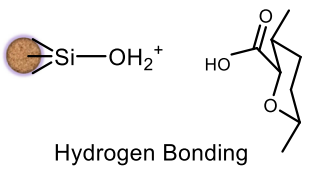

pH > pHzpc of Silica
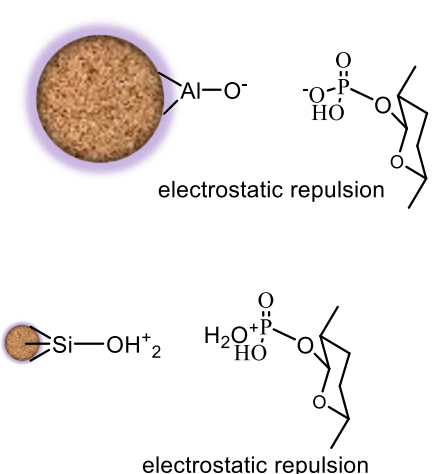

electrostatic repulsion

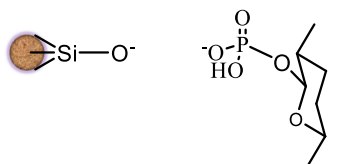

electrostatic repulsion cultured in the presence of $2 \& 0.2 \mathrm{wt} \%$ alumina or silica particles at $\mathrm{pH}$ values between 2 and 10 . The results showed increased bacterial growth at low $\mathrm{pH}$ in the presence of mineral particles compared to control solutions (Figure 7 and Tables S3-S6 and Figure S25).

The findings show that the presence of silica and alumina enhanced the growth of $E$. coli in the presence of a higher concentration of inorganic particles at $\mathrm{pH} 2$. This could be explained by the favorable proton or electrostatic interactions at low $\mathrm{pH}$ values in comparison to higher ones. In particular, the relative charge of silica are positive at $\mathrm{pH} 2$ (Figure 2) causing attraction between the negatively charged bacteria ${ }^{44}$ and the positively charged silica particles at this $\mathrm{pH}$ value. In the case of alumina, the mineral particles are positively charged between $\mathrm{pH} 2$ and 9 (Figure 2), with the positive charge declining with the increase of $\mathrm{pH}$. The attractive electrostatic interactions between the negatively charged bacteria and the positively charged alumina particles can therefore explain the increase in bacterial growth in the presence of both silica and alumina at low $\mathrm{pH}$ values. Increase in the $\mathrm{pH}$ values increases the overall negative charge of the bacteria and the mineral surfaces, impeding the sorption and therefore bacterial growth $^{34}$ which in the presence of silica dropped sharply compared to an equivalent solution at $\mathrm{pH} 5$, while in the case of alumina it saw a much smaller decrease at $\mathrm{pH} 5$, only diminishing to equal the lower concentration at neutral and higher $\mathrm{pH}$. Although there are other effects and interactions in these biological systems, these results indicate that the interaction of the bacterial extracellular matrix to inorganic surfaces is highly $\mathrm{pH}$ dependent, as the $\mathrm{pH}$ affects both electrostatic interactions and hydrogen-bonding potential. $^{1,18,22,44}$

The results support our hypothesis that the aqueous composition influences the binding of bacterial cell wall components to mineral surfaces because the growth of E. coli increased at solution conditions favorable for the presence of electrostatic, proton, or hydrogen bonding interactions.

\section{CONCLUSIONS}

This study has examined the solution conformation of $E$. coli 0111: B4 extruded LPS (S form), which plays a key part in the biofilm formation process. These polymers interact with the particulate solid matter within the solution, although electrostatic or proton interactions governing the adsorption process make them particularly sensitive to $\mathrm{pH}$. Polymers were isolated by centrifugation, characterized, and their adhesion to mineral surfaces measured via both fluorescence tagging and direct adsorption methods.

For the first time, studies of TRAMS have shown the change in conformational behavior of this biologically produced substance. Polymer mobility becomes increasingly restricted when exposed to solid surfaces, with the reduction in polymer rotation and diffusion matching data gathered from direct adsorption measurements. It was observed that more LPS is adsorbed to the surface of alumina than silica. We suggest that, in neutral conditions, electrostatic interactions are predominantly responsible for the adsorption of LPS on alumina 
a)

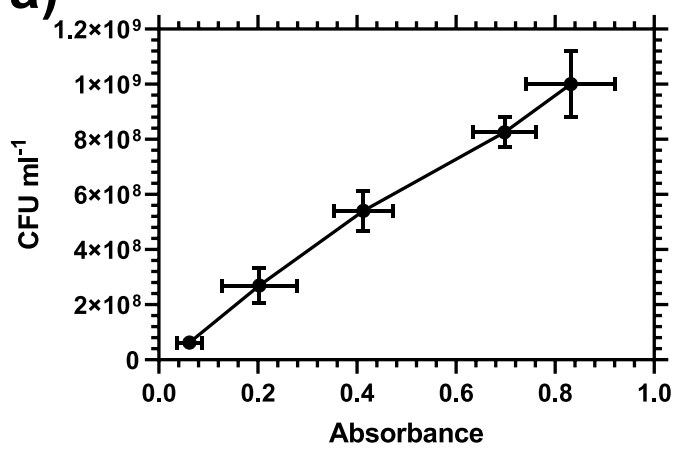

b)

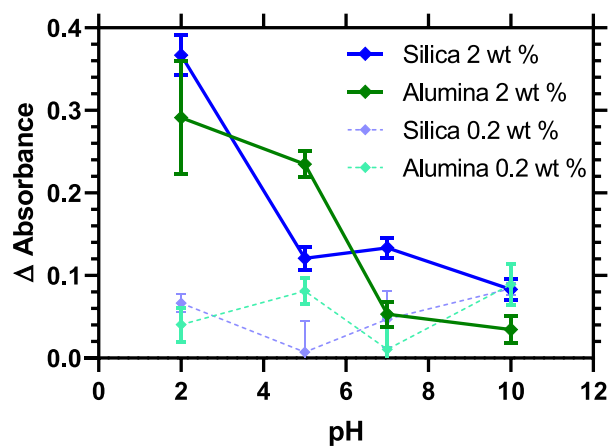

Figure 7. (a) Calibration curve of bacterial growth using absorbance measurements and cfu $\mathrm{mL}^{-1}$ measurements. (b) Relative absorbance of $10^{4} \mathrm{cfu} \mathrm{mL} \mathrm{m}^{-1}$ bacteria incubated with low (0.2) and high (2) wt \% silica/alumina at varying $\mathrm{pH}$. In all instanced $\Delta \mathrm{Abs}$ is shown compared to the same bacterial absorbance in the absence of inorganic particles.

particles, whereas weak forces, such as van der Waals, control the interaction between LPS and silica suspensions.

Interestingly, the ratio of adsorption of LPS onto alumina appears independent of whether the polymer is expanded or collapsed in the solution. Stronger adsorption was observed at low $\mathrm{pH}$ for both minerals than at high $\mathrm{pH}$ because of the changing conformation of the polymer. A combination of electrostatic and hydrogen bonding interactions is possible between LPS and mineral surfaces which depend on the conformation of the molecule and hence exposure to functional groups. Further molecular modeling work of LPS-mineral interactions may provide insights on the attraction and repulsion processes driving sorption.

\section{ASSOCIATED CONTENT}

\section{SI Supporting Information}

The Supporting Information is available free of charge at https://pubs.acs.org/doi/10.1021/acs.langmuir.9b02158.

Calculations of AmNS polymer loading, polymer characterization, fluorescence of AmNS, poly(acrylic acid) adsorption properties, and TRAMS raw data analysis (PDF)

\section{AUTHOR INFORMATION}

\section{Corresponding Authors}

Thomas Swift - School of Chemistry and Biosciences, University of Bradford, Bradford BD7 1DP, U.K.; (1) orcid.org/00000002-8616-8458; Email: t.swift@bradford.ac.uk

Maria E. Romero-González - Department of Geography, The University of Sheffield, Sheffield S10 2TN, U.K.; 10 orcid.org/
0000-0001-5808-5383; Email: m.romero-gonzalez@ qmul.ac.uk

\section{Authors}

Fateh El-Taboni - Department of Chemistry, University of Benghazi, Benghazi Qar Yunis 9480, Libya

Emily Caseley - School of Chemistry and Biosciences, University of Bradford, Bradford BD7 1DP, U.K.

Maria Katsikogianni - School of Chemistry and Biosciences, University of Bradford, Bradford BD7 1DP, U.K.

Linda Swanson - Department of Chemistry, The University of Sheffield, Sheffield S10 2TN, U.K.

Complete contact information is available at:

https://pubs.acs.org/10.1021/acs.langmuir.9b02158

\section{Notes}

The authors declare no competing financial interest.

\section{ACKNOWLEDGMENTS}

The authors thank the Libyan Ministry of Education for financial support during the experimental study. We thank the EPSRC funded consortium "Hard-soft matter interfaces: from understanding to engineering" (EP/I001514/1) for financial support. Emily Caseley, who assisted in the preparation and characterization of AmNS-LPS particles as an MRC Confidence in Concept funded postdoctoral researcher at the University of Bradford, (MC_PC_16038). We would also like to thank Dr Chien-Yi Chang (Ūniversity of Bradford) for helpful discussions on the role played by LPS in biofilm formation.

\section{REFERENCES}

(1) Parikh, S. J.; Chorover, J. ATR-FTIR Study of Lipopolysaccharides at Mineral Surfaces. Colloids Surf., B 2008, 62, 188-198.

(2) Meredith, T. C.; Aggarwal, P.; Mamat, U.; Lindner, B.; Woodard, R. W. Redefining the Requisite Lipopolysaccharide Structure in Escherichia Coli. ACS Chem. Biol. 2006, 1, 33-42.

(3) Bergstrand, A.; Svanberg, C.; Langton, M.; Nydén, M. Aggregation Behavior and Size of Lipopolysaccharide from Escherichia Coli O55:B5. Colloids Surf., B 2006, 53, 9-14.

(4) Hori, K.; Matsumoto, S. Bacterial Adhesion: From Mechanism to Control. Biochem. Eng. J. 2010, 48, 424-434.

(5) Atabek, A.; Camesano, T. A. Atomic Force Microscopy Study of the Effect of Lipopolysaccharides and Extracellular Polymers on Adhesion of Pseudomonas Aeruginosa. J. Bacteriol. 2007, 189, 85038509.

(6) Walker, S. L.; Redman, J. A.; Elimelech, M. Role of Cell Surface Lipopolysaccharides in Escherichia Coli K12 Adhesion and Transport. Langmuir 2004, 20, 7736-7746.

(7) Shrivastava, R.; Chng, S.-S. Lipid Trafficking across the GramNegative Cell Envelope. J. Biol. Chem. 2019, 294, 14175-14184.

(8) Jacobson, K. H.; Gunsolus, I. L.; Kuech, T. R.; Troiano, J. M.; Melby, E. S.; Lohse, S. E.; Hu, D.; Chrisler, W. B.; Murphy, C. J.; Orr, G.; et al. Lipopolysaccharide Density and Structure Govern the Extent and Distance of Nanoparticle Interaction with Actual and Model Bacterial Outer Membranes. Environ. Sci. Technol. 2015, 49, 1064210650.

(9) Okuda, S.; Sherman, D. J.; Silhavy, T. J.; Ruiz, N.; Kahne, D. Lipopolysaccharide Transport and Assembly at the Outer Membrane: The PEZ Model. Nat. Rev. Microbiol. 2016, 14, 337-345.

(10) Song, M. Y.; Jurng, J.; Park, Y.-K.; Kim, B. C. An Aptamer Cocktail-Functionalized Photocatalyst with Enhanced Antibacterial Efficiency towards Target Bacteria. J. Hazard. Mater. 2016, 318, 247254.

(11) Cho, M.; Chun, L.; Lin, M.; Choe, W.; Nam, J.; Lee, Y. Sensitive Electrochemical Sensor for Detection of Lipopolysaccharide 
on Metal Complex Immobilized Gold Electrode. Sens. Actuators, B 2012, 174, 490-494.

(12) Jayamohan, H.; Smith, Y. R.; Gale, B. K.; Mohanty, S. K.; Misra, M. Photocatalytic Microfluidic Reactors Utilizing Titania Nanotubes on Titanium Mesh for Degradation of Organic and Biological Contaminants. J. Environ. Chem. Eng. 2016, 4, 657-663.

(13) Nesper, J.; Lauriano, C. M.; Klose, K. E.; Kapfhammer, D.; Kraiß, A.; Reidl, J. Characterization of Vibrio Cholerae O1 El Tor GalU and GalE Mutants: Influence on Lipopolysaccharide Structure, Colonization, and Biofilm Formation. Infect. Immun. 2001, 69, 135145.

(14) Alshalchi, S. A.; Anderson, G. G. Expression of the Lipopolysaccharide Biosynthesis Gene LpxD Affects Biofilm Formation of Pseudomonas Aeruginosa. Arch. Microbiol. 2015, 197, 135145.

(15) Donlan, R. M. Biofilm Formation: A Clinically Relevant Microbiological Process. Clin. Infect. Dis. 2001, 33, 1387-1392.

(16) McCarty, S.; Jones, E. M.; Finnegan, S.; Woods, E.; Cochrane, C. A.; Percival, S. L. Chapter Eighteen - Wound Infection and Biofilms. Biofilms in Infection Prevention and Control; Academic Press: Boston, 2014; pp 339-358.

(17) Langley, S.; Beveridge, T. J. Effect of O-Side-ChainLipopolysaccharide Chemistry on Metal Binding. Appl. Environ. Microbiol. 1999, 65, 489-498.

(18) Makin, S. A.; Beveridge, T. J. The Influence of A-Band and BBand Lipopolysaccharide on the Surface Characteristics and Adhesion of Pseudomonas Aeruginosa to Surfaces. Microbiology 1996, 142, 299-307.

(19) Flemming, C. A.; Palmer, R. J.; Arrage, A. A.; Van Der Mei, H. C.; White, D. C. Cell Surface Physicochemistry Alters Biofilm Development of Pseudomonas Aeruginosa Lipopolysaccharide Mutants. Biofouling 1998, 13, 213-231.

(20) Santos, N. C.; Silva, A. C.; Castanho, M. A. R. B.; Martins-Silva, J.; Saldanha, C. Evaluation of Lipopolysaccharide Aggregation by Light Scattering Spectroscopy. ChemBioChem 2003, 4, 96-100.

(21) Ferris, F. G.; Beveridge, T. J. Site Specificity of Metallic Ion Binding in Escherichia Coli K-12 Lipopolysaccharide. Can. J. Microbiol. 2011, 32, 52-55.

(22) Jucker, B. A.; Harms, H.; Hug, S. J.; Zehnder, A. J. B. Adsorption of Bacterial Surface Polysaccharides on Mineral Oxides Is Mediated by Hydrogen Bonds. Colloids Surf., B 1997, 9, 331-343.

(23) Sparks, D. J.; Romero-González, M. E.; El-Taboni, E.; Freeman, C. L.; Hall, S. A.; Kakonyi, G.; Swanson, L.; Banwart, S. A.; Harding, J. H. Adsorption of Poly Acrylic Acid onto the Surface of Calcite: An Experimental and Simulation Study. Phys. Chem. Chem. Phys. 2015, 17, 27357-27365.

(24) Bergbreiter, D. E.; Tao, G.; Franchina, J. G.; Sussman, L. Polyvalent Hydrogen-Bonding Functionalization of Ultrathin Hyperbranched Films on Polyethylene and Gold. Macromolecules 2001, 34, 3018-3023.

(25) Swift, T.; Swanson, L.; Geoghegan, M.; Rimmer, S. The PHResponsive Behaviour of Poly(Acrylic Acid) in Aqueous Solution Is Dependent on Molar Mass. Soft Matter 2016, 12, 2542-2549.

(26) Ojeda, J. J.; Romero-González, M. E.; Bachmann, R. T.; Edyvean, R. G. J.; Banwart, S. A. Characterization of the Cell Surface and Cell Wall Chemistry of Drinking Water Bacteria by Combining XPS, FTIR Spectroscopy, Modeling, and Potentiometric Titrations. Langmuir 2008, 24, 4032-4040.

(27) Smith, T. A.; Ghiggino, K. P. A Review of the Analysis of Complex Time-Resolved Fluorescence Anisotropy Data. Methods Appl. Fluoresc. 2015, 3, 022001.

(28) Ruiz-Pérez, L.; Pryke, A.; Sommer, M.; Battaglia, G.; Soutar, I.; Swanson, L.; Geoghegan, M. Conformation of Poly(Methacrylic Acid) Chains in Dilute Aqueous Solution. Macromolecules 2008, 41, 2203-2211.

(29) Swift, T.; Seaton, C. C.; Rimmer, S. Poly(Acrylic Acid) Interpolymer Complexes. Soft Matter 2017, 13, 8736-8744.

(30) Chakraborty, I.; Mukherjee, I.; Haldar, U.; De, P.; Bhattacharyya, R. Monitoring Aggregation of a PH-Responsive
Polymer: Via Proton Exchange. Phys. Chem. Chem. Phys. 2017, 19, 17360 .

(31) Rice, A.; Wereszczynski, J. M. Lipopolysaccharide Simulations Are Highly Sensitive to Ion Parameters and Phosphate Charge State. Biophys. J. 2019, 116, 87A.

(32) Rodriguez-Loureiro, I.; Latza, V. M.; Fragneto, G.; Schneck, E. Conformation of Single and Interacting Lipopolysaccharide Surfaces Bearing O-Side Chains. Biophys. J. 2018, 114, 1624-1635.

(33) Jeon, C.; Park, J. Y.; Yoo, Y. J. Characteristics of Metal Removal Using Carboxylated Alginic Acid. Water Res. 2002, 36, 1814-1824.

(34) Wiśniewska, M. Temperature Effect on Adsorption Properties of Silica-Polyacrylic Acid Interface. J. Therm. Anal. Calorim. 2010, 101, $753-760$.

(35) Kubota, M.; Nakabayashi, T.; Matsumoto, Y.; Shiomi, T.; Yamada, Y.; Ino, K.; Yamanokuchi, H.; Matsui, M.; Tsunoda, T.; Mizukami, F.; et al. Selective Adsorption of Bacterial Cells onto Zeolites. Colloids Surf., B 2008, 64, 88-97.

(36) Lu, Q.; Wang, J.; Faghihnejad, A.; Zeng, H.; Liu, Y. Understanding the Molecular Interactions of Lipopolysaccharides during E. Coli Initial Adhesion with a Surface Forces Apparatus. Soft Matter 2011, 7, 9366-9379.

(37) Broos, J.; Visser, A. J. W. G.; Engbersen, J. F. J.; Verboom, W.; van Hoek, A.; Reinhoudt, D. N. Flexibility of Enzymes Suspended in Organic Solvents Probed by Time-Resolved Fluorescence Anisotropy. Evidence That Enzyme Activity and Enantioselectivity Are Directly Related to Enzyme Flexibility. J. Am. Chem. Soc. 1995, 117, 1265712663.

(38) Lee, J.; Martic, P. A.; Tan, J. S. Protein Adsorption on Pluronic Copolymer-Coated Polystyrene Particles. J. Colloid Interface Sci. 1989, $131,252-266$.

(39) Dobrynin, A. V.; Rubinstein, M. Effect of Short-Range Interactions on Polyelectrolyte Adsorption at Charged Surfaces $\dagger$. J. Phys. Chem. B 2003, 107, 8260-8269.

(40) Van Der Schee, H. A.; Lyklema, J. A Lattice Theory of Polyelectrolyte Adsorption. J. Phys. Chem. 1984, 88, 6661-6667.

(41) Patwardhan, S. V.; Emami, F. S.; Berry, R. J.; Jones, S. E.; Naik, R. R.; Deschaume, O.; Heinz, H.; Perry, C. C. Chemistry of Aqueous Silica Nanoparticle Surfaces and the Mechanism of Selective Peptide Adsorption. J. Am. Chem. Soc. 2012, 134, 6244-6256.

(42) Lambert, J.-F. Adsorption and Polymerization of Amino Acids on Mineral Surfaces: A Review. Origins Life Evol. Biospheres 2008, 38, $211-242$.

(43) Lau, P. C. Y.; Lindhout, T.; Beveridge, T. J.; Dutcher, J. R.; Lam, J. S. Differential Lipopolysaccharide Core Capping Leads to Quantitative and Correlated Modifications of Mechanical and Structural Properties in Pseudomonas Aeruginosa Biofilms. J. Bacteriol. 2009, 191, 6618-6631.

(44) Hamadi, F.; Latrache, H.; Elghmari, A. Determination of Escherichia Coli Negative Charge Concentration From XPS Data and Its Variation with PH. J. Surf. Anal. 2005, 12, 293-302. 